\title{
Melamine Nitrate: A Novel and Efficient Reagent for Regioselective Nitration of Phenols
}

\author{
Yong-qiang Chen and Hong Jiang \\ Department of Chemistry, College of Science, Huazhong Agricultural University, Wuhan, Hubei 430070, China
}

Correspondence should be addressed to Hong Jiang, jianghong0066@126.com

Received 2 April 2011; Accepted 5 May 2011

Academic Editor: Feihe Huang

Copyright ( $) 2011$ Y.-q. Chen and H. Jiang. This is an open access article distributed under the Creative Commons Attribution License, which permits unrestricted use, distribution, and reproduction in any medium, provided the original work is properly cited.

Melamine nitrate $(\mathrm{MN})$ as a novel nitration reagent was easily prepared. Regioselective nitration of phenols to their corresponding $o$-nitrophenols occurred using MN with p-toluenesulfonic acid as catalyst in good to excellent yields. A distinct advantage of this method is the easy separation of products by simple filtration.

\section{Introduction}

Nitration of aromatic compounds is one of the most important and widely studied reactions and industrial processes. The typical nitration procedure requires use of mixed acids such as concentrated nitric acid and sulfuric acid. Nitrophenols are important intermediates for the manufacture of drugs and pharmaceuticals [1]. But phenols are highly reactive; therefore the nitration of phenols by mixed acids is always associated with the formation of dinitro compounds, oxidized products, and unspecified resinous materials. So a lot of mild nitration processes for phenols have been developed to overcome these shortcomings. Especially, in recent years, various nitrate salts for phenols have been reported [2-10]. However, some of the nitrating reagents are poorly regioselective and uneconomical. Considering these concerns, there is still a good scope for research towards finding economic, mild reagents for regioselective nitration of phenols.

Melamine is a widely used fire retarder in polymers. The amino groups of melamine are stable to oxidation condition such as $\mathrm{H}_{2} \mathrm{O}_{2}$, in which it can form stable adduct with $\mathrm{H}_{2} \mathrm{O}_{2}$ $[11,12]$. This inspired us to think that melamine may be stable in oxidative acid such as nitric acid. So in this paper we prepared the melamine nitric acid complex (MN) (Figure 1) and used it as nitration reagent.
Herein we report this efficient and facile nitration procedure for phenols using MN (Scheme 1). The preparation of melaminium nitrate is simple by the direct reaction of melamine with nitric acid at room temperature.

\section{Results and Discussions}

Table 1 summarized the results of nitration of phenol by $\mathrm{MN}$ in different solvents such as $\mathrm{CCl}_{4}, \mathrm{CH}_{2} \mathrm{Cl}_{2}$, and $\mathrm{CHCl}_{3}$; the highest yield of 2-nitrophenol was isolated in acetone (Table 1, entry 1). So in the following reactions, acetone was used as solvent. Different other catalytic acids like, acetic acid, benzoic acid, and sulfuric acid were also tested but they either gave trace product (in acetic acid or benzoic acid) or very complicated products (in sulfuric acid); so ptoluenesulfonic acid was chosen as catalytic acid.

The results of nitration reactions of other phenolic compounds by using $\mathrm{MN}$ as nitrating reagent were summarized in Table 2.

Ortho-orientation relative to hydroxyl group and mononitration of phenolic compounds was observed. For example, 4-Methoxyl-2-nitrophenol was isolated in 96\% yield by the nitration of 4-methoxylphenol in acetone solution (Table 2, entries 2). In the cases of 4-methylphenol and 4phenylphenol, orth-nitro relative to the $\mathrm{OH}$ group products 
TABLE 1: Nitration of phenol with different solvents by MN.

\begin{tabular}{lccccc}
\hline Entry & Solvent & Yield (\%) & Entry & solvent & Yield $(\%)^{\mathrm{a}}$ \\
\hline 1 & Acetone & 90 & 3 & $\mathrm{CH}_{2} \mathrm{Cl}_{2}$ & 86 \\
2 & $\mathrm{CCl}_{4}$ & 82 & 4 & $\mathrm{CHCl}_{3}$ & 77 \\
\hline
\end{tabular}

${ }^{a}$ Isolated yields for 2-nitrophenol after silica gel chromatography.

TABle 2: Nitration of phenolic compounds with MN.

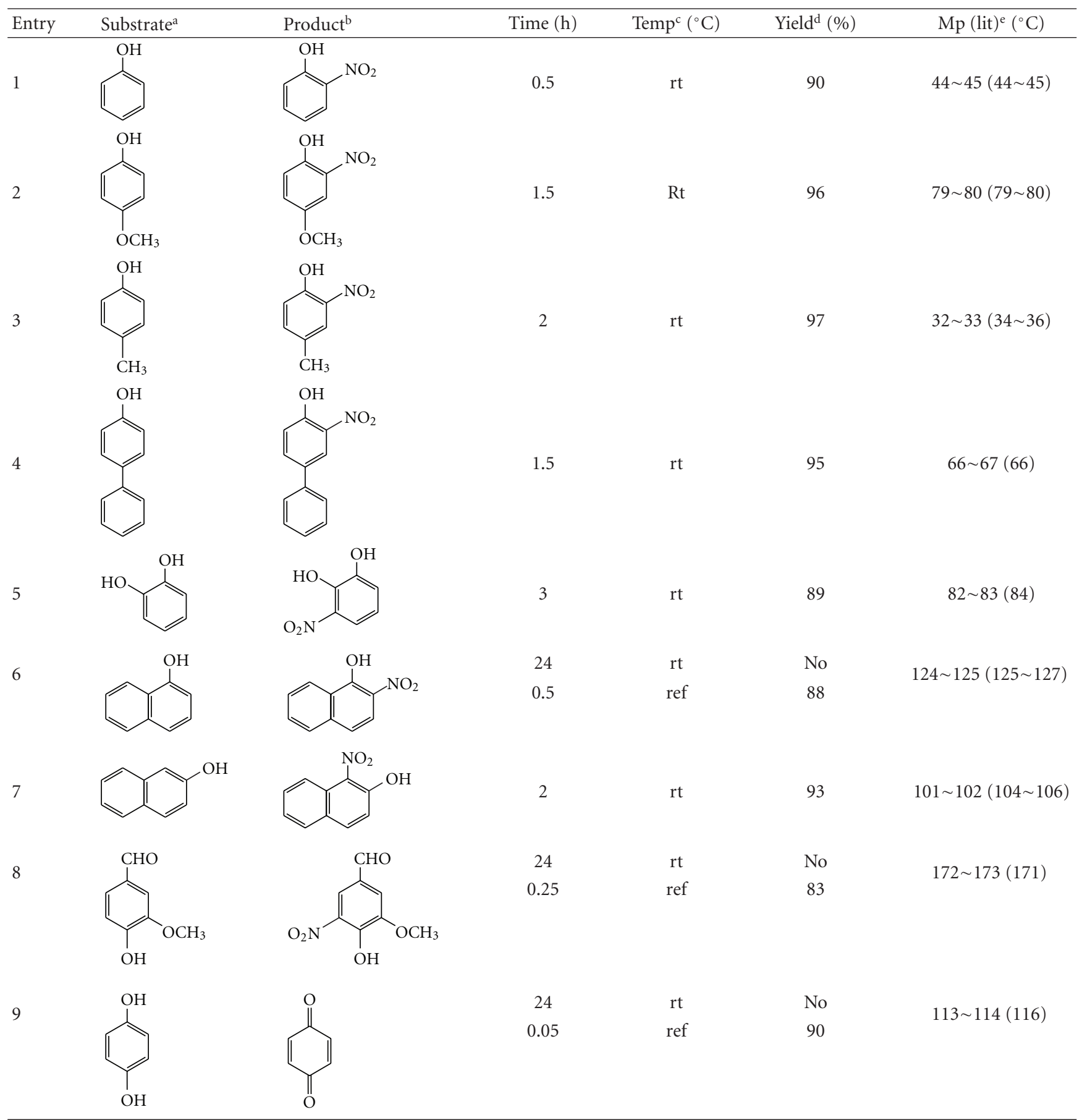

\footnotetext{
${ }^{a}$ For compounds resorcinol, phloroglucinol, 2-hydroxybenzaldehyde, 4-hydroxy benzaldehyde, methyl 2-hydroxybenzoate, 4-hydroxybenzoic acid, their results were not listed in this table because they could not be nitrated with $\mathrm{MN}$.

${ }^{b}$ All the products were characterized by ${ }^{1}$ H NMR, MS and IR (see supplementary material available on line at doi: 10.1155/2011/753142).

${ }^{c}$ ref means reflux.

${ }^{\mathrm{d}}$ Isolated yields after silica gel chromatography.

${ }^{\mathrm{e}}$ Dictionary of Organic Compounds.
} 
<smiles>Nc1nc(N)[n+]2c(n1)N[IH]C(=O)N([O-])O2</smiles>

$\mathrm{MN}$

FIgURe 1<smiles>[R]c1cccc([18OH])c1N=[W]</smiles>

Scheme 1

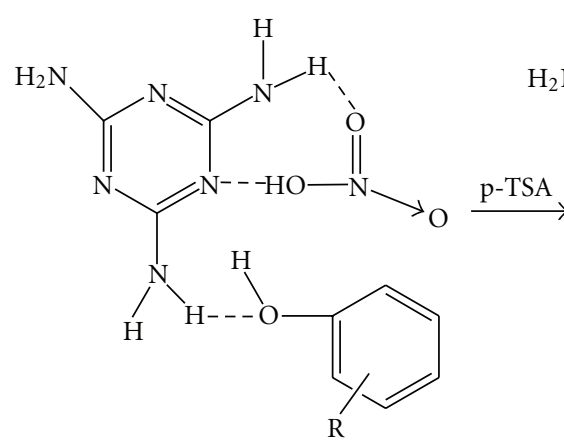<smiles>[R][X]c1cccc([N+](=O)[O-])c1O</smiles>

SCHEMe 2

in excellent yields was also produced. Although the corresponding 3-nitro-1, 2-benzenediol was obtained in $89 \%$ yield by the nitration of catechol (Table 2 , entry 5 ), under the same reaction conditions, the reactions of 1, 4-benzenediol, resorcinol, and phloroglucinol could not be carried out at room temperature. When 1, 4-benzenediol (Table 2, entry 9) was treated with $\mathrm{MN}$ under reflux for $24 \mathrm{~h}$, it was oxidized to para-benzoquinone. When resorcinol or phloroglucinol was refluxed with MN, complicated tarry products were produced (not shown in Table 2). The unsuccessful nitration for resorcinol and phloroglucinol may be ascribed to the sterically crowded factor between 1,3-disubstituted hydroxy groups which is hardly to be attacked by nitronium ion. For entry 6, the conversion of 1-naphthol to 2-nitro-1-naphthol occurred within $0.5 \mathrm{~h}$ under reflux, whereas it did not work at room temperature. In contrast with 1-naphthol, 2-naphthol could react with $\mathrm{MN}$ much easier resulting in 1-nitro-2naphthol at room temperature.

Though phenolic compounds bearing electron donating groups well behaved to afford the o-nitrophenolic compounds selectively, those with even moderately deactivating groups, such as 2-hydroxybenzaldehyde, 4-hydroxybenzaldehyde, methyl 2-hydroxybenzoate, and 4-hydroxybenzoic acid (all of them were not shown in Table 2) have no reaction at room temperature or under reflux by TLC monitor. However, the nitration of 3-methoxy-4-hydroxybenzaldehyde (entry 8 , Table 2 ) was successful, which may be ascribed to the two activating groups, hydroxyl and 
methoxyl, attached to the benzene ring. One more advantage of this procedure is that no dinitrophenol product was formed by increasing the amount of MN.

A mechanism for the pronounced ortho-orientation nitration of phenols is postulated as Scheme 2. A hydrogen bond can be formed between phenolic compounds and MN. The hydrogen cation provided by p-toluenesulfonic acid attacked the hydroxyl group of nitric acid leading to the formation of nitronium cation. The nitronium cation will attack the ortho-position of hydroxyl group of phenol much easier from steric factor, resulting in the formation of the corresponding ortho-nitrophenols.

\section{Conclusion}

MN can serve as a high ortho-orientation nitrating agent for phenolic compounds bearing electron donating groups with p-toluenesulfonic acid as catalyst. The reagent in this reaction is a comparatively clean, safe, and facile to operate.

\section{Experimental}

All the chemicals were obtained from China Chemical Reagent Company. All products are known compounds and were characterized by m.p., IR, ${ }^{1} \mathrm{H}$ NMR, and GC/MS. Melting points were determined on an RY-2 melting apparatus and are uncorrected. ${ }^{1} \mathrm{H}$ NMR data were acquired on a Bruker $\mathrm{AV} 400 \mathrm{MHz} \mathrm{CDCl}_{3}$, or DMSO-d6 was used as solvent using TMS as an internal standard. IR spectra were recorded on an Avatar 330 infrared spectrophotometer (KBr pellet); only the most significant absorption bands are reported $\left(\nu \max , \mathrm{cm}^{-1}\right)$. MS is performed on a Saturn 2000 mass spectrometer. Thin-layer chromatography (TLC) was performed on silica gel F254 plates using a $254 \mathrm{~nm}$ UV lamp (model UVG-54) or/and iodine vapor to monitor the progress of reactions.

4.1. Preparation of $M N$. In a round-bottomed flask $(250 \mathrm{~mL})$ equipped with a mechanic stirrer, a suspension of melamine $(3.1 \mathrm{~g}, 25 \mathrm{mmol})$ and $10 \mathrm{~mL} \mathrm{HNO}_{3}(20 \%, 32 \mathrm{mmol})$ was stirred at $20^{\circ} \mathrm{C}$ for $2 \mathrm{~h}$. Then the reaction mixture was transferred to a crystallizing dish for slow evaporation of water under a mild air flow. After 3 days, $\mathrm{MN}$ as a white solid was obtained.

4.2. General Procedure for the Nitration of Phenols. In a typical nitration procedure, to a stirring mixture of acetone $(15 \mathrm{~mL})$ and phenol $(0.56 \mathrm{~g}, 6 \mathrm{mmol})$ at room temperature, $\mathrm{MN}(1.3 \mathrm{~g}, 7 \mathrm{mmol})$ and the catalytic amount of $\mathrm{p}$ toluenesulfonic acid $(0.06 \mathrm{~g}, 0.4 \mathrm{mmol})$ were added. The mixture was stirred at room temperature for appropriate time. The progress of the reaction was monitored by TLC. At the end of the reaction, the mixture was filtered. Then, acetone was removed by evaporation to afford the crude product, which was chromatographed over silica gel to give the pure compound in high yield using hexane : ethyl acetate as eluents.

Similarly other phenolic compounds were nitrated under the similar conditions and their reaction times and yields are presented in Table 2. The compounds were confirmed by ${ }^{1} \mathrm{H}$ NMR, MS, and IR spectrum.

\section{Acknowledgment}

The authors thank the National Natural Science Foundation of China (Grant no. 20702016).

\section{References}

[1] D. A. Conlon, J. E. Lynch, F. W. Hartner, R. A. Reamer, and R. P. Volante, "Nitrous acid-catalyzed nitration of 4-bromo-2,5dichlorophenol. Observation of an unusually facile rearrangement of a 4-bromo-2-nitrophenol during nitration," Journal of Organic Chemistry, vol. 61, no. 18, pp. 6425-6429, 1996.

[2] M. A. Zolfigol, E. Ghaemi, and E. Madrakian, "Nitration of phenols under mild and heterogeneous conditions," Molecules, vol. 6, no. 7, pp. 614-620, 2001.

[3] H. B. Sun, R. Hua, and Y. Yin, "Highly efficient nitration of phenolic compounds in solid phase or solution using $\mathrm{Bi}\left(\mathrm{NO}_{3}\right)_{3} .5 \mathrm{H}_{2} \mathrm{O}$ as nitrating reagent," Journal of Organic Chemistry, vol. 70, no. 22, pp. 9071-9073, 2005.

[4] N. C. Ganguly, S. Dutta, M. Datta, and P. De, "Solid-state regioselective nitration of activated hydroxyaromatics and hydroxycoumarins with cerium (IV) ammonium nitrate," Journal of Chemical Research, no. 11, pp. 733-735, 2005.

[5] R. Rajagopal and K. V. Srinivasan, "Ultrasound promoted para-selective nitration of phenols in ionic liquid," Ultrasonics Sonochemistry, vol. 10, no. 1, pp. 41-43, 2003.

[6] S. A. Shackelford, M. B. Anderson, L. C. Christie et al., "Electrophilic tetraalkylammonium nitrate nitration. II. Improved anhydrous aromatic and heteroaromatic mononitration with tetramethylammonium nitrate and triflic anhydride, including selected microwave examples," Journal of Organic Chemistry, vol. 68, no. 2, pp. 267-275, 2003.

[7] B. Baghernejad, H. A. Oskooie, M. M. Heravi, and Y. S. Beheshtiha, " $\mathrm{KHSO}_{4}$ as an efficient catalytic system for the regiospecific nitration of phenols with metal nitrates," Chinese Journal of Chemistry, vol. 28, no. 3, pp. 393-396, 2010.

[8] H. Firouzabadi, N. Iranpoor, and M. A. Zolfigol, "A reinvestigation of nitration of phenols with metal nitrates under nonaqueous and aprotic conditions," Iranian Journal of Chemistry and Chemical Engineering, vol. 16, no. 2, pp. 48-58, 1997.

[9] J. J. P. Selvam, V. Suresh, K. Rajesh, S. R. Reddy, and Y. Venkateswarlu, "Highly efficient nitration of phenolic compounds by zirconyl nitrate," Tetrahedron Letters, vol. 47, no. 15 , pp. 2507-2509, 2006.

[10] A. K. Bose, S. N. Ganguly, M. S. Manhas et al., "Microwave promoted rapid nitration of phenolic compounds with calcium nitrate," Tetrahedron Letters, vol. 47, no. 12, pp. 1885$1888,2006$.

[11] T. Nagaishi, M. Matsumoto, and S. Yoshigana, "Thermal decomposition of the addition compound of melamine with hydrogen peroxide," Journal of Thermal Analysis, vol. 36, no. 1, pp. 55-60, 1990.

[12] G. Chehardoli and M. A. Zolfigol, "Melamine hydrogen peroxide (MHP): novel and efficient reagent for the chemoand homoselective and transition metal-free oxidation of thiols and sulfides," Phosphorus, Sulfur and Silicon and the Related Elements, vol. 185, no. 1, pp. 193-203, 2010. 


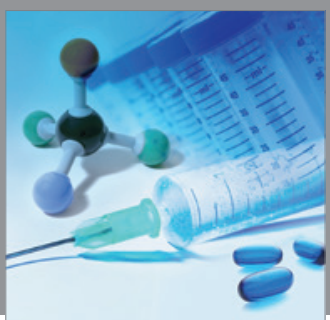

International Journal of

Medicinal Chemistry

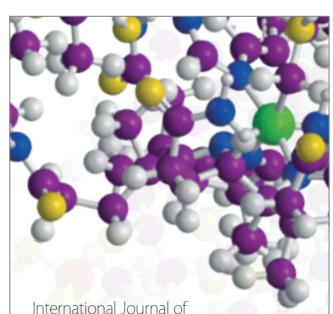

Carbohydrate Chemistry

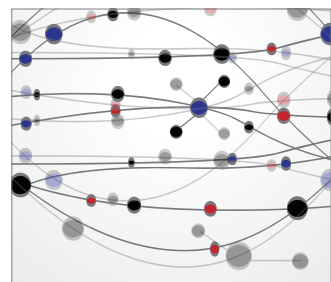

The Scientific World Journal
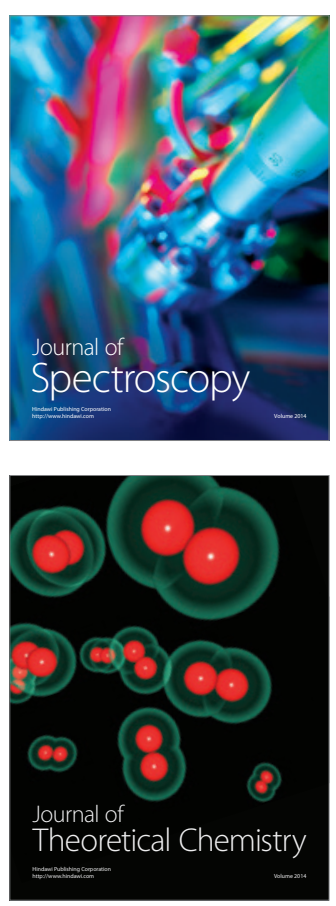
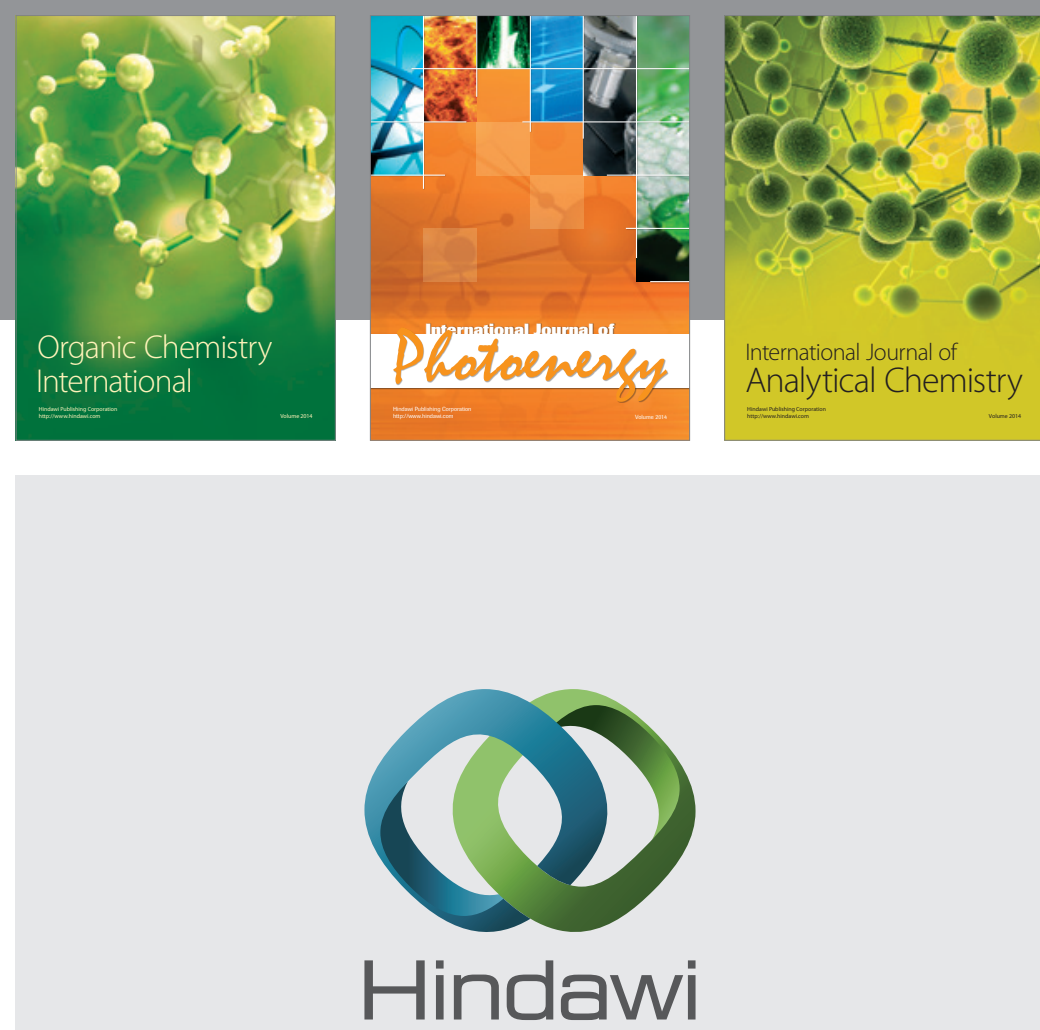

Submit your manuscripts at

http://www.hindawi.com
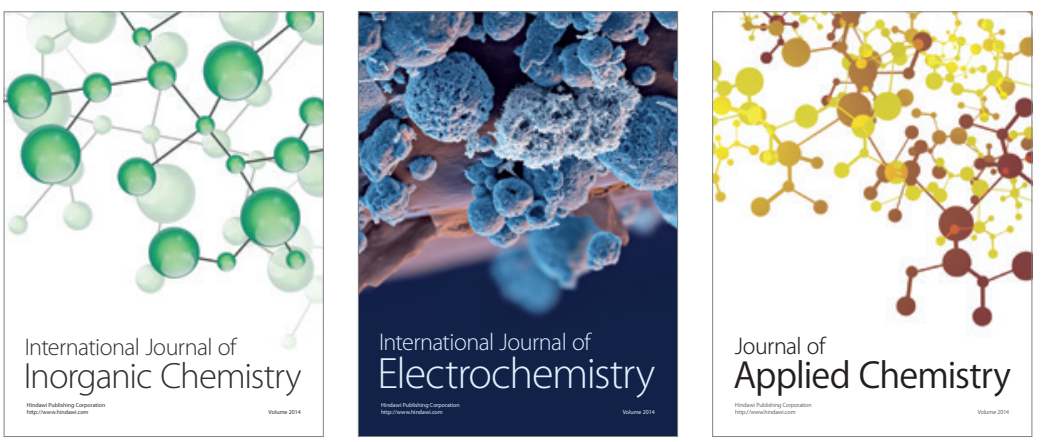

Journal of

Applied Chemistry
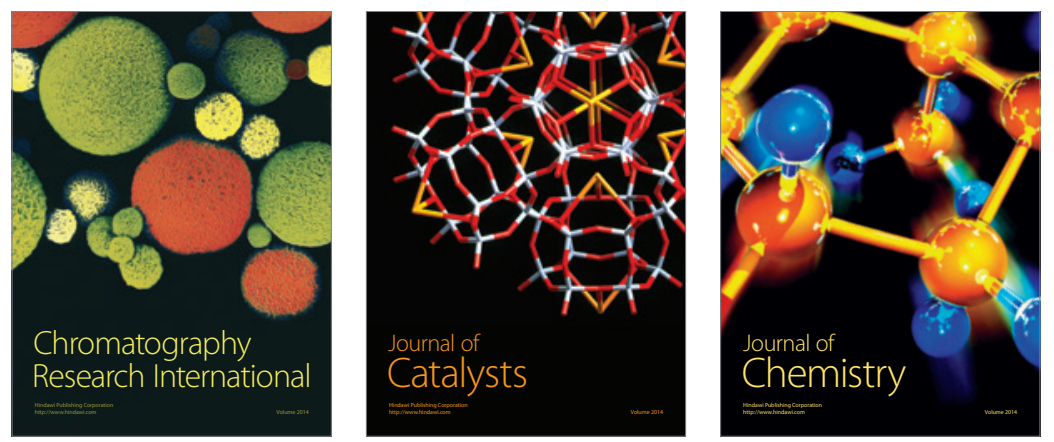
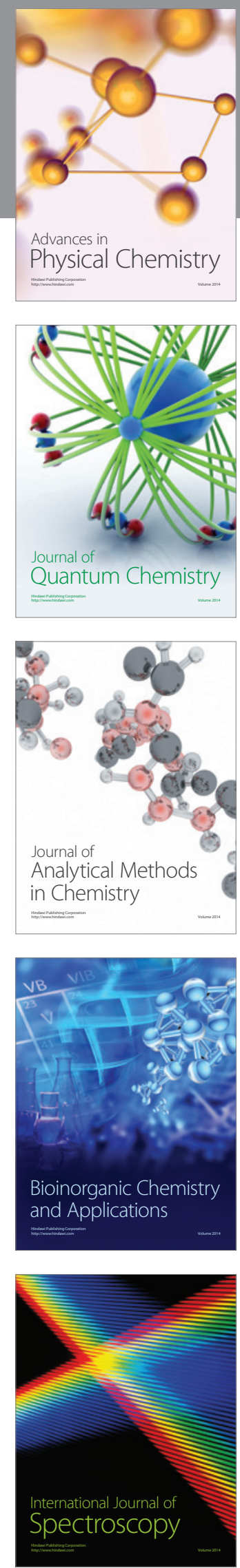